\title{
Prevalence of ocular and oculodermal melanocytosis in Spanish population with uveal melanoma
}

\begin{abstract}
Purpose The aim of this study was to determine the prevalence of ocular and oculodermal melanocytosis (ODM) among patients with uveal melanoma (UM) in a Spanish population.
\end{abstract}

Methods Retrospective review of the medical records of patients with ODM among patients with UM.

Results Ten (11 eyes) of 400 patients (2.7\%) with UM associated had ODM. The mean age at diagnosis of UM among patients with ODM was 62 years. One patient had bilateral tumours. UM was diagnosed during a routineexamination in two cases. All tumours were medium $(7 / 11)$ or large $(4 / 11)$ in size, with a mean maximum base of $13 \mathrm{~mm}$ and height of $7 \mathrm{~mm}$. No patient had extraocular extension or metastatic disease at diagnosis. Enucleation was done in five cases and I-125-brachytherapy in six. The mean follow-up was 43 months. One patient died because of metastasis 2 years after enucleation; one patient is currently on treatment of systemic metastasis $\mathbf{1 1}$ years after. Conclusions ODM is more frequent in spanish population with UM than in American population. Despite the risk of UM in ODM, it is often diagnosed late when a conservative treatment is not indicated. Eye (2012) 26, 159-162; doi:10.1038/eye.2011.257; published online 21 October 2011

Keywords: tumour; melanoma; ocular melanocytosis; oculodermal melanocytosis

\section{Introduction}

Ocular melanocytosis (OM), a congenital condition first described by the Japanese dermatologist Ota in $1939,{ }^{1}$ is characterised by
E Carreño ${ }^{1}$, MA Saornil ${ }^{1,2}$, C Garcia-Alvarez ${ }^{1,2}$, F Lopez-Lara2,3, JM De Frutos-Baraja ${ }^{2,3}$ and A Almaraz ${ }^{4}$

${ }^{1}$ Ophthalmology

Department, Hospital

Clinico Universitario,

Valladolid, Spain patients, ${ }^{5}$ but there is a clear association with the presence of uveal melanoma (UM) in Caucasians. ${ }^{6-8}$ Varying involvement of the orbit and meninges can occur. ${ }^{9}$

An association between UM and OM/ODM is supported strongly by previous findings such as the early onset of $\mathrm{UM}^{10}$ the ipsilaterality of the OM/ODM with the UM, and sectorial OM/ODM progressing to UM in the affected sector $^{11}$ as well as cases of bilateral and multifocal UM. ${ }^{10,12}$ The association of ODM with malignant melanomas in the orbit or intracranially also was reported. ${ }^{13-15}$ Despite that, patients with OM/ODM sometimes do not have adequate follow-up.

The aim of this paper was to determine the relative incidence of OM/ODM in patients with UM in Spanish population.

\section{Case reports}

Patients from the Intraocular-Tumours-Unit of 'Hospital Clínico Universitario de Valladolid' from 1992 to 2009 with concurrent UM and OM/ODM were included. This study was a case series. Diagnosis of UM was based on ophthalmoscopic appearance and ultrasonographic features. Pigmented lesions $>1 \mathrm{~mm}$ in height or base $>5 \mathrm{~mm}$ were included based on the criteria of the Collaborative Ocular Melanoma Study (COMS). ${ }^{16}$ The COMS size classification and the TNM classification system $^{17}$ were used.
${ }^{2}$ Intraocular Tumors Referral Unit National Health System, Hospital Clínico Universitario Valladolid, Spain

${ }^{3}$ Radiotherapy Department, Hospital Clínico Universitario de Valladolid, Spain

${ }^{4}$ Epidemiology and Preventive Medicine Department, Valladolid University, Spain

Correspondence: E Carreño, Department of Ophthalmology, Hospital Clínico Universitario, C/ Ramón y Cajal 3, Valladolid 47005, Spain Tel: + 3498342 0000; Fax: + 34983257511 . E-mail: carregnito@ gmail.com

Received: 6 May 2011 Accepted in revised form: 15 August 2011 Published online: 21 October 2011

Presented in part as an electronic poster at the 17th Congress of the European Society of Ophthalmology, June 2009, Amsterdam, The Netherlands. 
Diagnosis of ocular melanocytosis was based on biomicroscopic and ophthalmoscopic appearance, and oculodermal melanocytosis was diagnosed in the presence of dermal involvement.

Demographic information; onset; extent of melanocytosis, fundus-eye examination, B-modeultrasound with vector- $\mathrm{A}$; measurement of tumour diameter, height, size, shape, and location were recorded. Ancillary tests were used to detect extraocular extension and identify systemic metastasis. Treatment included enucleation or I-125-brachytherapy. Pathology data were classified according to the modifications of Callender'sclassification of UM at the Armed Forces Institute of Pathology. ${ }^{18}$ Follow-up examinations were conducted every 6 months during the first 5 years and yearly thereafter.

Data were codified in a database designed in Microsoft Access. A descriptive analysis was performed.

Eleven eyes (2.7\%) (10 patients) of 401 (400 patients) in the UM database of the Intraocular Tumours Unit, with data recorded over the course of 17years, had OM/ODM. Demographic information and clinical features are recorded in Table 1. All patients presented a tumour ipsilateral to the eye with OM/ODM. All cases of OM/ODM showed a diffuse involvement, with affection of episclera, and uvea, plus skin involvement in the cases of ODM. No extraocular extension or metastatic disease was observed at the time of diagnosis of the UM in any patient.

Three patients underwent enucleation at 'Hospital Clínico de Valladolid'; one had the mixed-cell melanoma (case 2), one the spindle-cell melanoma (case 3), and one the epitheloid-cell melanoma (case 6).

In six cases treated with I-125-brachytherapy, the mean-dose to apex was $82.25 \mathrm{~Gy}$. No intraocular tumour recurrence was observed during the follow-up.
One patient died because of metastasis 2 years after enucleation (case 2), and one patient is receiving systemic treatment for metastasis 11years after enucleation (case 3).

\section{Discussion}

OM/ODM affect only about $0.038 \%$ of the general Caucasian population, ${ }^{19}$ and, in this series, $2.7 \%$ of patients with UM had OM/ODM, indicating that $\mathrm{OM} / \mathrm{ODM}$ is about 71 times more common in the UM population. Another series reported it to be about 35 times more common in patients with UM. ${ }^{8}$ Using Bayes' theorem and previous data, and a prevalence for UM of $7.5 \times 10^{-5},{ }^{20}$ the lifetime prevalence of UM in patients with OM/ODM was $5.32 \times 10^{-3}$.

Unfortunately, there are no studies determining the prevalence of OM/ODM in a Spanish population, and the prevalence of $0.038 \%$ is from a general Caucasian population in the United States. ${ }^{19}$

Compared with other series, the current series presents a higher prevalence of OM/ODM in UM population. The prevalence reported ranged between 1.24 and $1.36 \% .^{6-8}$ The $2.7 \%$ prevalence rate in the current series is statistically higher than the $1.24 \%^{7}$ rate $(P=0.03)$ and in the limits of statistical significance compared with the $1.36 \%{ }^{6}$ rate $(P=0.057)$. This disparity could be explained by differences between populations and environmental conditions. The decreasing north-to-south gradient of the incidences of UM in Europe was reported..$^{21}$ The differences could result from the different eye colours, ${ }^{21}$ or exposure to solar radiation. ${ }^{22}$ It is then possible to assume that the risk factors for UM, such as OM/ODM, have different roles depending on the geographic area.

Although OM/ODM is a risk factor for UM, with a higher prevalence in our population, most patients have

Table 1 Clinical and tumour characteristics

\begin{tabular}{|c|c|c|c|c|c|c|c|c|c|c|c|c|c|}
\hline \multirow{2}{*}{$\begin{array}{l}\text { Case } \\
\text { No }\end{array}$} & \multirow{2}{*}{$\begin{array}{l}\text { Age } \\
\text { (Years) }\end{array}$} & \multirow[t]{2}{*}{ Gender } & \multirow[t]{2}{*}{ Eye } & \multirow{2}{*}{$\begin{array}{l}O M / \\
O D M\end{array}$} & \multirow{2}{*}{$\begin{array}{l}\text { Symptoms } \\
\text { At Onset }\end{array}$} & \multicolumn{2}{|c|}{ Ultrasound } & \multirow[t]{2}{*}{ Size } & \multirow[t]{2}{*}{ Localization } & \multirow[t]{2}{*}{ Shape } & \multirow[t]{2}{*}{ Treatment } & \multirow{2}{*}{$\begin{array}{l}\text { Systemic } \\
\text { Metastasis }\end{array}$} & \multirow{2}{*}{$\begin{array}{c}\text { Follow-Up } \\
\text { (months) }\end{array}$} \\
\hline & & & & & & $\begin{array}{l}\text { Maximum } \\
\text { base (mm) }\end{array}$ & $\begin{array}{c}\text { Height } \\
(\mathrm{mm})\end{array}$ & & & & & & \\
\hline 1 & 63 & M & OD & $\mathrm{OM}$ & No & 13.00 & 4.45 & Medium & Choroid & NODULAR & BRACHYTHERAPY & No & 144 \\
\hline 2 & 42 & $\mathrm{~F}$ & OS & $\mathrm{OM}$ & Yes & 16.10 & 2.93 & Large & Choroid & INFILTRATIVE & ENUCLEATION & YES & 15 \\
\hline 3 & 31 & M & OS & OM & Yes & 13.30 & 5.10 & Medium & Choroid & NODULAR & ENUCLEATION & YES & 90 \\
\hline 4 & 79 & M & OD & OM & Yes & 20.00 & 14.80 & Large & Choroid & MUSHROOM & ENUCLEATION & No & - \\
\hline 5 & 56 & M & OD & OM & Yes & 9.79 & 4.58 & Medium & Choroid & NODULAR & BRACHYTHERAPY & No & - \\
\hline 6 & 84 & $\mathrm{~F}$ & OS & ODM & Yes & 18.00 & 13.00 & Large & Choroid & MUSHROOM & ENUCLEATION & No & 48 \\
\hline 7 & 78 & M & OS & OM & No & 11.43 & 7.63 & Medium & Choroid & MUSHROOM & BRACHYTHERAPY & No & 24 \\
\hline 8 & 40 & $\mathrm{~F}$ & OS & ODM & Yes & 7.45 & 8.06 & Medium & Choroid & MUSHROOM & BRACHYTHERAPY & No & 9 \\
\hline 9 & 76 & M & OD & $\mathrm{OM}$ & Yes & 16.80 & 9.70 & Large & $\begin{array}{l}\text { Ciliary } \\
\text { Body }\end{array}$ & MUSHROOM & ENUCLEATION & No & - \\
\hline \multirow[t]{2}{*}{10} & \multirow[t]{2}{*}{75} & \multirow[t]{2}{*}{ M } & \multirow[t]{2}{*}{$\mathrm{BE}$} & \multirow[t]{2}{*}{$\mathrm{OM}$} & \multirow[t]{2}{*}{ Yes } & 10.63 & 3.74 & Medium & Choroid & NODULAR & BRACHYTHERAPY & No & 13 \\
\hline & & & & & & 12.69 & 8.70 & Medium & Choroid & MUSHROOM & BRACHYTHERAPY & No & 2 \\
\hline SD & 19.07 & & & & & 3.90 & 3.86 & & & & & & 49.74 \\
\hline
\end{tabular}

Abbreviations: SD, Standard deviation; M, Male; F, Female; OD, Right eye; OS, Left eye; BE, Both eyes; OM, Ocular Melanocytosis; ODM, Oculodermal melanocytosis. 
not had adequate follow-up; the main reason for the diagnosis was the development of visual symptoms. Most UM are diagnosed when they are medium to large in size, resulting in a high rate of enucleation. When the tumour is detected early, conservative treatment with brachytherapy is possible and effective and can preserve the eye and, in some cases, the visual acuity.

In conclusion, although OM/ODM are important riskfactors for UM, with a higher prevalence in our population, most patients do not have adequate followup. Yearly ocular examinations are recommended to preserve the eye and vision, and improve the prognosis.

\section{Summary}

\section{What was known before}

- Ocular melanocytosis and oculodermal melanocytosis are more common in Asian patients, but there is a clear association with the presence of uveal melanoma in Caucasians. The prevalence reported in patients with uveal melanoma ranged between 1.24 and $1.36 \%$ among series.

\section{What this study adds}

- Compared with other series, the current series presents a higher prevalence of ocular melanocytosis and oculodermal melanocytosis in uveal melanoma population $(2.7 \%)$. It is possible to assume that the risk factors for uveal melanoma, such as ocular melanocytosis and oculodermal melanocytosis, have different roles depending on the geographic area and clinical features of the population. Although oculodermal melanocytosis is a risk factor for uveal melanoma, with a higher prevalence in our population, most patients have not had adequate follow-up; the main reason for the diagnosis was the development of visual symptoms, despite the longstanding clinical signs of episcleral hyperpigmentation, iris heterochromia, or dermal melanocytosis. Therefore, most uveal melanomas are diagnosed when they become symptomatic and are medium-to-large in size, resulting in a high rate of enucleation, even though in many cases the tumour is easily detectable by ophthalmoscopy. When the tumour is detected early, conservative treatment with brachytherapy is possible and effective and can preserve the eye and, in some cases, the visual acuity.

\section{Conflict of interest}

The authors declare no conflict of interest.

\section{Acknowledgements}

The study was performed with informed consent, following all the guidelines for experimental investigations required by the Institutional Review Board or Ethics Committee to which all authors are affiliated.

\section{References}

1 Ota M, Tamino H. A variety of nevus frequently encountered in Japan, nevus fusco-coeruleus ophthalmomaxilaris and its relation to pigmentary changes in the eye. Tokyo Med J 1939; 63: 1242-1244.

2 Fitzpatrick TB, Kitamura H, Kukita A, Zeller R. Ocular and dermal melanocytosis. AMA Arch Ophthalmol 1956; 56(6): 830-832.

3 Teekhasaenee C, Ritch R, Rutnin U, Leelawongs N. Ocular findings in oculodermal melanocytosis. Arch Ophthalmol 1990; 108(8): 1114-1120.

4 Yanoff M, Zimmerman LE. Histogenesis of malignant melanomas of the uvea. 3 . The relationship of congenital ocular melanocytosis and neurofibromatosis in uveal melanomas. Arch Ophthalmol 1967; 77(3): 331-336.

5 Leung AK, Kao CP, Cho HY, Siu MP, Choi MC, Sauve RS. Scleral melanocytosis and oculodermal melanocytosis (nevus of Ota) in Chinese children. J Pediatr 2000; 137(4): 581-584.

6 Gonder JR, Shields JA, Albert DM, Augsburger JJ, Lavin PT. Uveal malignant melanoma associated with ocular and oculodermal melanocytosis. Ophthalmology 1982; 89(8): 953-960.

7 Velazquez N, Jones IS. Ocular and oculodermal melanocytosis associated with uveal melanoma. Ophthalmology 1983; 90(12): 1472-1476.

8 Singh AD, De Potter P, Fijal BA, Shields CL, Shields JA, Elston RC. Lifetime prevalence of uveal melanoma in white patients with oculo(dermal) melanocytosis. Ophthalmology 1998; 105(1): 195-198.

9 Gonder JR, Nichol J, Augsburger JJ, Shields JA. Ocular and oculodermal melanocytosis. Can J Ophthalmol 1985; 20(5): 176-178.

10 Shields CL, Eagle RC, Ip MS, Marr BP, Shields JA. Two discrete uveal melanomas in a child with ocular melanocytosis. Retina 2006; 26(6): 684-687.

11 Shields JA, Shields CL, Davidson R, Eagle Jr RC. Iris melanoma arising from sector congenital ocular melanocytosis in a child. Cornea 2009; 28(10): 1191-1193.

12 Honavar SG, Shields CL, Singh AD, Deminci H, Rutledge BK, Shields JA et al. Two discrete choroidal melanomas in an eye with ocular melanocytosis. Surv Ophthalmol 2002; 47(1): 36-41.

13 Theunissen P, Spincemaille G, Pannebakker M, Lambers J. Meningeal melanoma associated with nevus of Ota: case report and review. Clin Neuropathol 1993; 12(3): 125-129.

14 Kiratli H, Bilgic S, Satilmis M. Ocular melanocytosis associated with intracranial melanoma. Br J Ophthalmol 1996; 80(11): 1025.

15 Sagar HJ, Ilgren EB, Adams CB. Nevus of Ota associated with meningeal melanosis and intracranial melanoma. Case report. J Neurosurg 1983; 58(2): 280-283.

16 Singh AD. Clinical ophthalmic oncology. Elsevier Saunders: Edinburgh, 2007.

17 Sobin LH, Gospodarowicz MK, Wittekind C. International Union against Cancer. TNM classification of malignant tumours, 7th edn. Wiley-Blackwell: Chichester, West Sussex, UK; Hoboken, NJ, 2010.

18 McLean IW, Foster WD, Zimmerman LE, Gamel JW. Modifications of Callender's classification of uveal melanoma at the Armed Forces Institute of Pathology. Am J Ophthalmol 1983; 96(4): 502-509. 
19 Gonder JR, Ezell PC, Shields JA, Augsburger JJ. Ocular melanocytosis. A study to determine the prevalence rate of ocular melanocytosis. Ophthalmology 1982; 89(8): 950-952.

20 Shields JA, Shields CL. Intraocular tumors : an atlas and textbook, 2nd edn. Lippincott Williams \& Wilkins: Philadelphia, 2008.
21 Virgili G, Gatta G, Ciccolallo L, Capocaccia R, Biggeri A Crocetti $\mathrm{E}$ et al. Incidence of uveal melanoma in Europe. Ophthalmology 2007; 114(12): 2309-2315.

22 Yu GP, Hu DN, McCormick SA. Latitude and incidence of ocular melanoma. Photochem Photobiol 2006; 82(6): 1621-1626. 